\title{
Spontaneous Remission of Primary Hyperparathyroidism in a Patient with Neurofibromatosis Type 1: Case Report
}

\author{
França MM¹, Santos AB ${ }^{1}$, Hirosawa RM1, Souza GL ${ }^{1}$, Tagliarini JV², Mazeto GMFS ${ }^{1}$ and Nunes VS ${ }^{1 *}$
}

${ }^{1}$ Department of Internal Medicine, Botucatu Medical School, Sao Paulo, State University/Unesp, Sao Paulo, Brazil

${ }^{2}$ Department of Ophthalmology and Otolaryngology, Botucatu Medical School, Sao Paulo, State University/Unesp, Sao Paulo, Brazil

\begin{abstract}
Neurofibromatosis type 1 (NF1) is an autosomal dominant multisystem disorder affecting approximately 1 in 3500 individuals. Patients with the disorder can develop carcinoid tumors, medullary thyroid carcinoma, pheochromocytoma and tumor of the hypothalamus. The association of NF1 with Primary Hyperparathyroidism (HPP) is very rare. We report a 56-year-old woman with NF1 who was referred to our service because of nephrolithiasis. Physical examination revealed the characteristic signs of NF1, and her laboratory calcium profile was compatible with HPP. The patient was referred for parathyroidectomy, but during the surgical work-up she underwent spontaneous remission of her HPP. This case is significant not only for the rarity of this presentation in NF1 patients, but also because of the spontaneous remission of HPP.
\end{abstract}

Keywords:NeurofibromatosisType1;PrimaryHyperparathyroidism; Autosomal dominant disease

\section{Introduction}

Neurofibromatosis type 1 (NF1) or von Recklinghausen disease is an autosomal dominant disorder affecting approximately 1 in 3500 individuals, with $50 \%$ of the cases being familial and the others occurring by de novo mutation [1-3]. Affected individuals can develop a variety of benign and malignant tumors; the most common are neurofibromas which are a peripheral nervous system tumor.

The diagnostic criteria for NF1 are met in an individual who has two or more of the clinical features: 6 or more café-au-lait macules $>5 \mathrm{~mm}$ in diameter in prepubertal and $>15 \mathrm{~mm}$ in postpubertal individuals (the longest diameter of each lesion is measured); 2 or more neurofibromas of any type or 1 plexiform neurofibroma; freckling in the axillary or inguinal regions; optic glioma; 2 or more Lisch nodules (iris hamartomas); a distinctive bony lesion such as sphenoid dysplasia or thinning of the cortex of a long bone, with or without pseudoarthrosis; and a first-degree relative (parent, sibling, or offspring) with NF1 based on the previous criteria [4]. In addition to these findings, affected patients present an increased risk for neoplasias of the central nervous system, including, ependimomas, meningiomas, astrocytomas; and some endocrine tumors, including pheochromocytomas, parathyroid neoplasias, carcinoid tumors, and, most frequently, medullary carcinomas of the thyroid [5], which often occur in association with pheochromocytomas [6].

HPP results from hyper secretion of Parathyroid Hormone (PTH); in $85 \%$ to $90 \%$ of cases it is caused by an adenoma in 1 of the parathyroid glands [7]. It is the most common cause of hypercalcemia diagnosed in an ambulatory setting $[7,8]$ and can occur at any age, but most frequently from 40 to 65 years, with a female:male predominance of 3:1. The incidence in Rochester-Minnesota during 1993-2001 was estimated to be 21.6 per 100,000 person-years [9]. Although the sporadic form is most common, about $10 \%$ of cases are familial and may be isolated or associated with other autosomal-dominant endocrine neoplasias such as Multiple Endocrine Neoplasia (MEN) types 1 and 2, and hyperparathyroidism-jaw tumor syndrome.

The association of NF1 with HPP has been reported, but is uncommon. We present a patient with both conditions, along with spontaneous remission of her hyperparathyroidism.

\section{Case Report}

A postmenopausal 56-year-old woman, who had been diagnosed with NF1 34 years previously and had a 3-year history of arterial hypertension, was referred to our service for investigation of nephrolithiasis. Two of her 4 children, whom she had with her first cousin, and 1 of her 4 grandchildren also had NF1 (Figure 1).

Her physical examination revealed numerous neurofibromas on the face, cervical region, trunk, and extremities; and café-au-lait spots larger than $1.5 \mathrm{~cm}$ on her back, abdomen, and thorax. Ophthalmologic examination showed numerous Lisch nodules, and she also had pulsatile exophthalmos of the left eye.

Results of laboratory investigations showed that the calcium profile was compatible with HPP (total serum calcium, $11.9 \mathrm{mg} / \mathrm{dL}$ [normal: 8.4-10.2 mg/dL]; PTH, $213 \mathrm{pg} / \mathrm{dL}$ [normal: 11-65 pg/dL]; 24-hour urinary calcium, $7.3 \mathrm{mg} / \mathrm{kg}$; and serum phosphorus $2.2 \mathrm{mg} /$

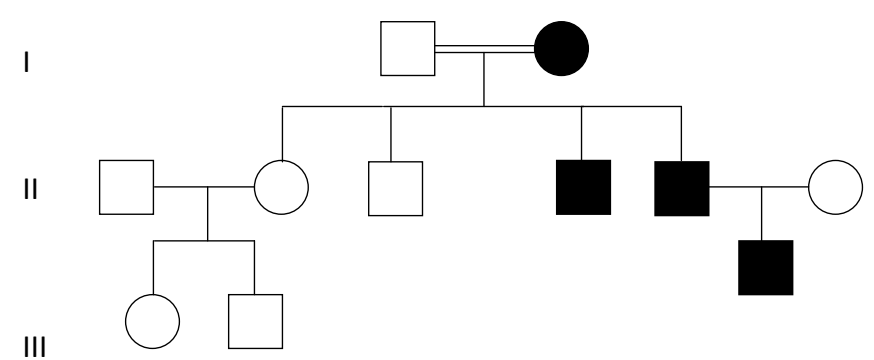

Figure 1: The patient had with her first cousin 4 children, two of them have Neurofibromatosis Type 1 and 1 of her 3 grandchildren also had the syndrome.

*Corresponding author: Vania dos Santos Nunes, Department of Internal Medicine Botucatu Medical School, Sao Paulo, State University/Unesp, Sao Paulo, Brazil, Tel: 5514381162 13; Fax: 5514388222 38; E-mail: vsnunes@fmb.unesp.br

Received May 02, 2012; Accepted June 15, 2012; Published June 25, 2012

Citation: França MM, Santos AB, Hirosawa RM, Souza GL, Tagliarini JV, et al (2012) Spontaneous Remission of Primary Hyperparathyroidism in a Patient with Neurofibromatosis Type 1: Case Report. J Clin Case Rep 2:156. doi:10.4172/21657920.1000156

Copyright: (c) 2012 França MM, et al. This is an open-access article distributed under the terms of the Creative Commons Attribution License, which permits unrestricted use, distribution, and reproduction in any medium, provided the original author and source are credited. 
dL [normal: $2.5-4.5 \mathrm{mg} / \mathrm{dL}])$. Serum albumin and renal function were normal. Scintigraphy and ultrasonography of the parathyroids did not reveal abnormalities. Bone densitometry showed osteoporosis at the femoral neck (T-score, -2.87). Magnetic resonance imaging of the head demonstrated findings compatible with a plexiform neurofibroma originating in the left temporal region with infiltration of adjacent structures, gliosis in the left frontal lobe, probable arachnoid cyst in the left Sylvian fissure, and agenesis of the wing of the left sphenoid bone. Results of screening for pheochromocytoma, performed by testing for the presence of plasma catecholamines and urinary metanephrines, were negative.

Because of the findings and because her hypercalcemia (serum calcium $>11 \mathrm{mg} / \mathrm{dL}$ ) had been present at least 1 year, the patient was referred for parathyroidectomy. However, spontaneous HPP remission occurred during preoperative programming (total serum calcium, 9.7 $\mathrm{mg} / \mathrm{dL}$; PTH, $59.2 \mathrm{pg} / \mathrm{dL} ; 24$ hour urinary calcium and phosphorus, 138 $\mathrm{mg} / \mathrm{dL}$ and $3.8 \mathrm{mg} / \mathrm{dL}$, respectively). Normal serum calcium and PTH levels have been maintained for 2 years.

The patient's children were also screened for the disease. They were provided with information regarding the hereditary nature of NF1 and the need for regular specialized medical follow-ups. Because of the uncommon association of NF1 with HPP, the calcium profiles of all the NF1-affected children and grandchild were determined. The results of the HPP screening examinations were negative.

\section{Discussion}

The NF1 gene, located at chromosome 17q11.2, has been mapped and cloned [10] it codes for neurofibromin, which is a protein expressed in tissues such as brain, kidney, spleen, and thymus [11]. Mutations in NF1 lead to a functional loss of this protein, thereby provoking a wide array of clinical findings, including the association of NF1 with diverse benign and malignant tumors. A study of a defined Swedish population found that neuroendocrine tumors such as, pheochromocytoma, and C-cell hyperplasia of the thyroid, represented $10 \%$ of all tumors that appeared in patients with NF1 [11].

Approximately 13 patients with NF1 and HPP have been described, but the pathogenesis of this association has not yet been well elucidated [12]. Dayle et al. [6] reported the first cases in the literature, and presented the hypothesis that there could be a genetic link between parathyroid adenoma (originating in endoderm) and NF1 (originating in neuroectoderm). However, Chakrabarti et al. [13] interpreted the association as another variant of MEN type $2 \mathrm{~B}$.

There is great variety of expression in NF1 patients, and there is also a series of characteristics that only occur in a minority of cases $[2,14]$. Some of these variations can reflect different mutations in NF1, while others might be associated with environmental or other external factors [15]. However, genetic evaluations of the association between NF1 and HPP have never been reported; thus, to ascertain the mechanism of this association further, new studies are necessary.

In the last few decades, along with the increase in the number of diagnosed HPP cases, the profiles of clinical and laboratory presentations and therapeutic interventions have undergone changes. In general, familial HPP presents with severe hypercalcemia; and the management of these patients differs from sporadic HPP due to the variability of the presentations including: penetrance, delay in the onset of symptoms, severity of hypercalcemia, propensity for parathyroid cancer (hyperparathyroidism jaw-tumor syndrome), viability and precision in the evaluation of the status of the mutation carrier, and elevated post-parathyroidectomy relapse rate [16].

There have been a few reported cases of spontaneous remission of HPP [17]. Remissions in these cases were generally attributed to hemorrhage and/or infarct of the adenoma [18-23]. This phenomenon has been termed "autoparathyroidectomy" or "parathyroid apoplexia" because of similarities with pituitary apoplexia [24]. Elangovan et al. [24] also proposed that the rapid growth of an adenoma might lead to a vascular event that is insufficient for producing an infarct but sufficient for reducing the supply of oxygen, leading to reduced production of PTH.

Regarding clinical presentation the patients can have hypocalcemia with or without tetania, followed by a period of normocalcemia or/ and recurrence of the disease. In rare cases, patients can present with signs and symptoms of cervical mass or mediastinal hemorrhage due to extra capsular hemorrhage of the adenoma. Although most patients are symptomatic, this phenomenon can be mild and the patients can have no clinical disorders [25]. In the majority of the cases reported in the literature, surgical treatment was ultimately performed, while only a few patients were treated conservatively, under periodical clinical and biochemical follow-up [24].

Nylen et al. [22] proposed a classification scheme for parathyroid apoplexy based on the extent of hemorrhage and clinical characteristics. The same patient can present with acute symptoms of hypocalcemia, or even with acute hypercalcemia caused by copious release of excess $\mathrm{PTH}$, followed by a period of normocalcemia and, finally, recurrence of the disease. The same patient can also present with asymptomatic reductions of calcium and PTH levels [25].

The routine use of one or more localizing studies commonly identifies the parathyroid tumor in patients with single-gland disease; but in some cases the localizing studies can be negative or discordant and these patients should have intra-operative PTH levels monitored or have a bilateral neck exploration to ensure a high rate of biochemical cure [22]. Comparisons of different imaging methods have demonstrated the superiority of parathyroid scintigraphy for preoperative localization [26]. One systematic review of the medical literature showed that the overall sensitivity of dual-phase ${ }^{99 \mathrm{~m}} \mathrm{Tc}$ sestamibi scintigraphy in comparison with high-resolution Ultrasonography (US) was $88 \%$ versus $78 \%$ for single adenomas, $30 \%$ versus $16 \%$ for double adenomas, and $44 \%$ versus $35 \%$ for multiplegland hyperplasia [27].

In conclusion, we described a patient with a clinical picture typical of NF1, in whom associated HPP was diagnosed during investigation of nephrolithiasis. Despite being a classical association, it is very rare. This patient manifested criteria for surgical intervention; however, she underwent spontaneous clinical remission of HPP during preoperative evaluation. Despite the rarity of HPP and, in this case, spontaneous remission, HPP can be associated with NF1, which should be remembered for this group of patients.

\section{References}

1. Theos A, Korf BR, American College of Physicians; American Physiological Society. (2006) Pathophysiology of neurofibromatosis type 1. Ann Intern Med 144: 842-849.

2. Riccardi VM (1993) Genotype, malleotype, phenotype, and randomness: lessons from neurofibromatosis-1 (NF-1). Am J Hum Genet 53: 301-304.

3. North K (1993) Neurofibromatosis type 1: review of the first 200 patients in an Australian clinic. J Child Neurol 8: 395-402. 
Citation: França MM, Santos AB, Hirosawa RM, Souza GL, Tagliarini JV, et al. (2012) Spontaneous Remission of Primary Hyperparathyroidism in a Patient with Neurofibromatosis Type 1: Case Report. J Clin Case Rep 2:156. doi:10.4172/2165-7920.1000156

4. Ferner RE (2007) Neurofibromatosis 1 and neurofibromatosis 2: a twenty first century perspective. Lancet Neurol 6: 340-351.

5. Greinwald J, Derkay CS, Schechter GL (1996) Management of massive head and neck neurofibromas in children. Am J Otolaryngol 17: 136-142.

6. Daly D, Kaye M, Estrada RL (1970) Neurofibromatosis and hyperparathyroidism-a new syndrome? Can Med Assoc J 103: 258-259.

7. Rodgers SE, Lew JI, Solorzano CC (2008) Primary hyperparathyroidism. Curr Opin Oncol 20: 52-58.

8. Bilezikian JP, Brandi ML, Rubin M, Silverberg SJ (2005) Primary hyperparathyroidism: new concepts in clinical, densitometric and biochemical features. J Intern Med 257: 6-17.

9. Wermers RA, Khosla S, Atkinson EJ, Achenbach SJ, Oberg AL, et al. (2006) Incidence of primary hyperparathyroidism in Rochester, Minnesota, 19932001: an update on the changing epidemiology of the disease. J Bone Miner Res 21: 171-177.

10. Shen MH, Harper PS, Upadhyaya M (1996) Molecular genetics of neurofibromatosis type 1 (NF1). J Med Genet 33: 2-17.

11. Zoller ME, Rembeck B, Oden A, Samuelsson M, Angervall L (1997) Malignant and benign tumors in patients with neurofibromatosis type 1 in a defined Swedish population. Cancer 79: 2125-2131.

12. Kodama H, lihara M, Okamoto T, Obara T (2007) Water-clear cel parathyroid adenoma causing primary hyperparathyroidism in a patient with neurofibromatosis type 1: report of a case. Surg Today 37: 884-887.

13. Chakrabarti S, Murugesan A, Arida EJ (1979) The association of neurofibromatosis and hyperparathyroidism. Am J Surg 137: 417-420.

14. Easton DF, Ponder MA, Huson SM, Ponder BA (1993) An analysis of variation in expression of neurofibromatosis (NF) type 1 (NF1): evidence for modifying genes. Am J Hum Genet 53: 305-313.

15. Sawada S, Florell S, Purandare SM, Ota M, Stephens K, et al. (1996) Identification of NF1 mutations in both alleles of a dermal neurofibroma. Nat Genet 14: 110-112

16. Marx SJ, Simonds WF, Agarwal SK, Burns AL, Weinstein LS, et al. (2002)
Hyperparathyroidism in hereditary syndromes: special expressions and special managements. J Bone Miner Res 17: N37-N43.

17. Pereira FA, Brandao DF, Elias J Jr, Paula FJ (2007) Parathyroid adenoma apoplexy as a temporary solution of primary hyperparathyroidism: a case report. J Med Case Rep 1: 139.

18. Mir R, Gerold T, Khan S, Weitz J (1993) Spontaneous infarction of parathyroid adenoma: case report and literature review. Head Neck 15: 566-568.

19. McLatchie GR, Morris EW, Forrester A, Fogelman Autoparathyroidectomy: a case report. Br J Surg 66: 552-553.

20. Hotes LS, Barzilay J, Cloud LP, Rolla AR (1989) Spontaneous hematoma of a parathyroid adenoma. Am J Med Sci 297: 331-333.

21. Onoda N, Miyakawa M, Sato K, Demura H, Uchida E (1994) Spontaneous remission of parathyroid adenoma followed with ultrasonographic examinations. J Clin Ultrasound 22: 134-136.

22. Nylen E, Shah A, Hall J (1996) Spontaneous remission of primary hyperparathyroidism from parathyroid apoplexy. J Clin Endocrinol Metab 81 : 1326-1328.

23. Natsui K, Tanaka K, Suda M, Yasoda A, Yonemitsu S, et al. (1996) Spontaneous remission of primary hyperparathyroidism due to hemorrhagic infarction in the parathyroid adenoma. Intern Med 35: 646-649.

24. Elangovan L, Felsenfeld AJ, Kleeman CR (1999) Spontaneous resolution and recurrence of hypercalcemia in primary hyperparathyroidism--anecdota observations with potential implications for parathyroid pathophysiology in renal disease. Nephrol Dial Transplant 14: 2323-2327.

25. Kovacs KA, Gay JD (1998) Remission of primary hyperparathyroidism due to spontaneous infarction of a parathyroid adenoma. Case report and review of the literature. Medicine (Baltimore) 77: 398-402.

26. Eslamy HK, Ziessman HA (2008) Parathyroid scintigraphy in patients with primary hyperparathyroidism: ${ }^{99 \mathrm{~m} T c}$ sestamibi SPECT and SPECT/CT. RadioGraphics 28: 1461-1476.

27. Ruda JM, Hollenbeak CS, Stack BC Jr (2005) A systematic review of the diagnosis and treatment of primary hyperparathyroidism from 1995 to 2003. Otolaryngol Head Neck Surg 132: 359-372.
Submit your next manuscript and get advantages of OMICS Group submissions

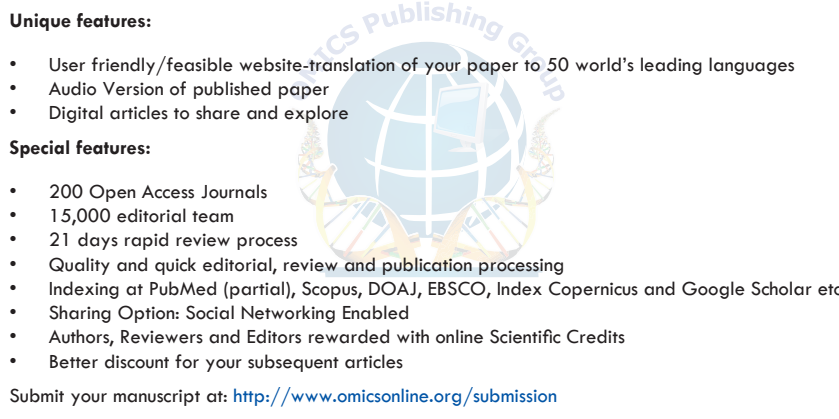

